\title{
DO FIRST-YEAR STUDENTS NEED ASSISTANCE IN ADOPTING HIGHER LEVEL OF LEARNING STRATEGIES?
}

\author{
Milenkova Liljana ${ }^{1}$, Srbinovski Mile $^{2}$ \\ ${ }^{\mathbf{1}}$ Institute of Medical Histology and Embryology, Faculty of Medicine, Ss Cyril and \\ Methodius University in Skopje, R. North Macedonia \\ ${ }^{2}$ Faculty of Technical Sciences, Mother Teresa University in Skopje, R. North Macedonia \\ e-mail: liljana.milenkova@gmail.com
}

\begin{abstract}
Introduction: This study aimed to estimate the level to which the students at the beginning of medical studies are familiarized with strategies for learning in order to explore where and how to assist at the very beginning of their learning.

Methods: A total of 368 1st to 6th year medical students at Ss. Cyril and Methodius University, Skopje, (North Macedonia) filled out the Motivated Strategies for Learning Questionnaire. In this questionnaire-based, cross-sectional, observational study emphasis was given to the first-year students $(n=109)$. Cohort distribution was determined according to scores expressing the level of practicing instruments of each learning strategy. Percentiles and lowest scores were used for tracing the least adopted strategies.

Results: Majority of the first-year students (52.49\%) use learning strategies at medium level, $26.60 \%$ at high and $20.89 \%$ at low level. For three subscale areas the percentile of students practicing at low level is especially high $(39.45 \%$ for critical thinking, $40.36 \%$ for peer learning and $36.69 \%$ for help seeking). For these subscales also students' scores have the lowest values.

Conclusion: Our first-year students use a different level of learning strategies. As $20.89 \%$ of students practice less than $55 \%$ of the instruments of each learning strategy and critical thinking, peer learning and help seeking (shown to be less adopted) are basic instruments for deeper and effective learning, the need to assist the first-year students in better adopting learning strategies is obvious. MSLQ

Keywords: medical students, first-year, learning strategies, extent of implementation,

\section{Introduction}

Medical students strive to become competent and reflective practitioners able to apply medical skills to different scenarios. To that extent, possessing good understanding of medical knowledge and skills for deeper thinking and critical analysis during unforeseen situations is vital. These crucial abilities should be learned during studies. They are attainable to those who adopt deeper learning approach based on ability to proactively select and use different strategies to reach learning goals.

Deep learning approach emphasizes understanding, relating, having interest in ideas and focusing on the concept applicable to problem solving. This approach is motivated by recognition the vocational relevance of the subject material [1].
\end{abstract}


Learning strategies are mental operations that a student can do to facilitate the completion of the task [2]. They can be defined as behaviors and thoughts in which a learner engages and which are intended to influence his encoding process. Learning strategies are steps taken by learner in order to select, acquire, organize and integrate new knowledge [3]. In turn, enhancing the learning positively affects the learner's motivational or affective state. Self-regulation of cognition and behavior are important aspects of learning and the extent to which students become self-regulators of their own learning influences their academic success [4]. Self-regulated learning is a cyclical process, where students make plans for the task, monitor their performance and reflect on the outcome. The cycle then repeats as the student uses the reflection to adjust and prepare for the next task. The process is not one-size-fits-all; it should be tailored for individual students and for specific learning tasks [5].

Since learning strategies have a direct impact on a student's academic achievements, we have conducted a study to examine the extent of implementation of learning strategies by students of general medicine studies at the Ss. Cyril and Methodius University, Faculty of Medicine in Skopje, North Macedonia. Emphasis was given to students attending early curriculum stage.

The aim of this study was to set off the starting point of the learning methodology of the first-year medical students.

The study was guided by the following questions:

1. To what extent do first-year students use strategies for effective learning?

2. Are there students still poorly familiarized with learning strategies?

3. Which of the learning strategies are less known to the first-year students?

Understanding how our students learn could provide significant input into developing services aimed at usefully correctively intervene and help strengthen students' learning skills.

Self-regulated learning, learning approach and learning strategies have attracted attention in medical education research. Studies have been conducted for various purposes: to determine the predominant learning type of their learning approach [6]; to correlate the learning approach to learning and academic performance [1]; to correlate students' motivated strategies with their academic performance [7] and test anxiety association with self-regulated learning scores [8]. Other studies have been conducted to identify factors influencing approaches to studying [9]; to evaluate the influence of demography, background, previous educational qualification, study habits and even social networking activity [10]; to relate student's motivation and self-regulated learning with their academic performance [11].

There are few credible instruments used for the purposes of those studies. For the purposes of our pilot study, the Learning Strategy section of the Motivated Strategy for Learning Questionnaire (MSLQ) developed by Pintrich, Smith, Garcia \& McKeachie [12] was chosen to assess the extent of learning strategy usage in terms of their presence in the studying process in general, not in particular courses. The results are intended to serve towards creating effective studying policies of the school and action towards aiding the students in acquiring those studying modalities.

The Motivated Strategy for Learning Questionnaire is one of the most widely used instruments for the evaluation of self-regulated learning as a reliable and useful tool that can be adapted to a number of different purposes for researchers, instructors and students according to Pinch et al. [13]. Several studies for estimating the psychometric properties of cognitive selfregulation scales [14-16] showed that cognitive and metacognitive self-regulation scales from MSLQ are able to measure students' learning strategies in a reliable and valid manner. Rotgans's and Schmidt's study [17] confirmed that MSLQ could be used at the general curriculum level. Currently, the MSLQ has been translated, adapted and applied to students from countries 
such as Argentina, Australia, Brazil, China, Colombia, Egypt, Iran, Mexico, South Africa, Spain, Turkey, United States, among others.

As this survey is a complementary segment of the project "Introduction of small-group active learning-how students' activities and the teacher's role in learning are being changed", the study has received Ethics Committee approval.

\section{Methodology}

Instrument: The Motivated Strategies for Learning Questionnaire (MSLQ) is designed and developed by a team of researchers from the National Center for Research to Improve Postsecondary Teaching and Learning (NCRIFFAL) and the School of Education at the University of Michigan. In this study the learning strategies section from MSLQ was taken to assess the extent of learning strategies usage from students of general medicine at the Ss. Cyril and Methodius University in Skopje.

Learning strategies section is based on a general cognitive model of learning and information processing and includes three general scales of learning strategies: a) cognitive strategies; b) meta-cognitive strategies and c) learning resources management, with 50 items. Cognitive strategies like select, organize and elaborate the information of the topics of study enable the student interpreting and understanding the topics [18]. Metacognition enables the students to control or self-regulate their learning processes $[18,19]$. Resources management strategies refer to the administration of resources such as time to study, anti-distractors management, social interaction and peer support for learning, among others [20]. This strategy section includes 9 subscales: rehearsal -4 items, organization of ideas -4 items, elaboration of ideas - 6 items, critical thinking -5 items (cognitive component); metacognition -12 items (metacognitive component); time and study environment management -8 items, effort regulation -4 items, peer learning -3 items and help seeking -4 items (resources management component). The questionnaire employs 7-point Likert scale, from 1 (does not apply to me) to 7 (applies to me strongly). Scales are constructed by taking the mean of the items that make up that scale. Final mean score for each subscale is obtained by dividing the sum of points acquired for the particular subscale with the number of its items. Higher values of score indicate higher level of use of learning strategies.

In order to be used in different languages and social contexts from which it was originally designed, a process of adjustment of the instrument is required [21]. The aim of the process of adaptation is that the translated and adapted instrument has psychometric properties comparable to the original instrument [21]. In North Macedonia, Shurbanovska O. and BlazhevskaStoilkova B. [22] adapted and validated the MSLQ in a population of university students. This version in Macedonian language was given to our participants.

Data collecting: For this study data were collected through voluntary anonymous online survey running from 25th of May until 10th of June 2020, for all students of general medicine. Detailed information for the aim and feedback was offered two weeks preceding the online survey.

Sample: A total of 368 students voluntarily accepted to participate in this survey. The sample was heterogeneous due to participation of various number of students from each academic year: 109 respondents from 1st year; 104 from 2nd; 73 from 3rd; 45 from 4th; 15 from 5th and 22 from 6th academic year. In this study emphasis was given to first-year students $(n=109)$.

Data analysis: To obtain profound insight into extent of use of the learning strategies, three levels of learning strategy mastering were defined, derived from the premise that profound learning and comprehension demand having mastered over $55 \%$ of the strategies. Participants were categorized according to their scores expressing the level of practicing instruments of each learning strategy. Level 1 group were students who utilized up to $55 \%$ of the 
instruments (range of score up to 3,85); level 2 group those who utilized from 55\% to 84\% (range of scores 3.85 to 5.94) and level 3 group students who used over $85 \%$ of instruments (range of scores 5.95-7.0).

The criteria for assessment related to the aim of this study were: measuring internal consistency of this study application with Cronbach's alpha; descriptive statistics (percent, average and standard deviation) for analysis frequency data; determining significance of difference among the means of three group of students by t-test as a type of inferential statistic; determining group mean scores of each subscale; analysis of variables of level 1 group of students for identifying the less adopted strategies.

\section{Results}

The extent to which the cohort of the first-year students use strategies for effective learning is given in Table 1. Results are presented by mean value of the score and standard deviation. Taken as a whole, respondents use strategies for effective learning at the intermediate level (mean 4.94). The highest score values pertain to elaboration and organization strategy while the lowest score values pertain to critical thinking and help seeking. The reliability and internal consistency of this study application expressed by Cronbach's alpha is 0.90, indicating an excellent precision. The alpha coefficients range from 0.44 (time \& study environment) to 0.84 (critical thinking), with most of the alphas above 0.60 .

Table 1. Subscale group average scores and internal reliability of the instrument

\begin{tabular}{|c|c|c|c|c|}
\hline \multirow[b]{2}{*}{ Subscale } & \multirow[b]{2}{*}{ Mean } & \multirow[b]{2}{*}{ Std. Dev. } & \multicolumn{2}{|c|}{ Internal reliability } \\
\hline & & & $\begin{array}{c}\text { Original } \\
\text { application }^{\mathrm{a}}\end{array}$ & $\begin{array}{l}\text { This study } \\
\text { application }\end{array}$ \\
\hline \multicolumn{5}{|l|}{ Cognitive } \\
\hline Rehearsal strategy & 5.21 & 1.30 & 0.69 & 0.61 \\
\hline Elaboration strategy & 5.55 & 1.20 & 0.75 & 0.58 \\
\hline Organization strategy & 5.47 & 1.25 & 0.64 & 0.71 \\
\hline Critical thinking & 4.27 & 1.50 & 0.80 & 0.84 \\
\hline \multicolumn{5}{|l|}{ Metacognitive } \\
\hline $\begin{array}{l}\text { Self-regulating the process of learning } \\
\text { Resource use }\end{array}$ & 4.87 & 0.90 & 0.79 & 0.69 \\
\hline Time \& study environment & 4.98 & 0.99 & 0.76 & 0.44 \\
\hline Effort regulation & 5.37 & 1.25 & 0.69 & 0.67 \\
\hline Peer learning & 4.29 & 1.76 & 0.76 & 0.77 \\
\hline Help seeking & 4.27 & 1.26 & 0.52 & 0.57 \\
\hline
\end{tabular}

Note: ${ }^{a}$ Pintrich et al., 1991

The distribution of the first-year students according to level of practicing strategies is presented in Table 2. Students utilizing less than 55\% of the learning strategies represent $20.89 \%$ of the cohort. The majority of students $(52.49 \%)$ are practicing medium level of learning strategies (using $55 \%$ to $84 \%$ of the instruments). High level ( $85 \%$ and over) of strategies utilize $26.6 \%$ of the students.

Regarding different subscales, rehearsal, elaborating, organizing, self-regulating, the time and study environment monitoring and effort regulating strategies are used at medium and high level by most students. A significantly lower number of participants utilizes high or medium level of critical thinking, peer learning and help seeking. For these three strategies, the percentile of students practicing at low level is very high. $39.45 \%$ of participants are practicing only low level of critical thinking, $40.36 \%$ low level of peer learning and $36.69 \%$ low level of help seeking. 
Table 2. First-year cohort distribution

\begin{tabular}{|c|c|c|c|c|c|c|}
\hline \multirow[t]{2}{*}{ Subscale } & \multicolumn{2}{|c|}{$\begin{array}{c}\text { Level 1 } \\
\text { (low) } \\
\text { less than 55\% }\end{array}$} & \multicolumn{2}{|c|}{$\begin{array}{c}\text { Level 2 } \\
\text { (medium) } \\
\text { 55\% to } 84.9 \%\end{array}$} & \multicolumn{2}{|c|}{$\begin{array}{c}\text { Level } 3 \\
\text { (high) } \\
85 \% \text { and above }\end{array}$} \\
\hline & $\mathbf{n}$ & $\%$ of the cohort & $\mathbf{n}$ & $\%$ of the cohort & $\mathbf{n}$ & $\%$ of the cohort \\
\hline Rehearsal strategy & 17 & 15.59 & 54 & 49.54 & 38 & 34.86 \\
\hline Elaboration strategy & 9 & 8.25 & 54 & 49.54 & 46 & 42.20 \\
\hline Organization strategy & 11 & 10.09 & 46 & 42.20 & 52 & 47.70 \\
\hline Critical thinking & 43 & 39.45 & 50 & 45.87 & 16 & 14.67 \\
\hline $\begin{array}{l}\text { Self-regulating the } \\
\text { process of learning }\end{array}$ & 14 & 12.84 & 85 & 77.98 & 10 & 9.17 \\
\hline $\begin{array}{l}\text { Time \& study } \\
\text { monitoring }\end{array}$ & 13 & 11.92 & 76 & 69.72 & 20 & 18.34 \\
\hline Effort regulation & 14 & 12.84 & 54 & 49.54 & 41 & 37.61 \\
\hline Peer learning & 44 & 40.36 & 39 & 35.77 & 26 & 23.85 \\
\hline Help seeking & 40 & 36.69 & 57 & 52.29 & 12 & 11.00 \\
\hline average \pm SD & & $\begin{array}{c}20.89 \% \pm 12.75 \\
\mathrm{~L} 1 \cdot \mathrm{L} 2\end{array}$ & & $\begin{array}{c}52.49 \% \pm 13.11 \\
\mathrm{~L} 2 \cdot 3\end{array}$ & & $26.60 \% \pm 13.38$ \\
\hline t- test & & $t=29.28$ & & $t=25.57$ & & $\mathrm{t}=4.30$ \\
\hline & & $p<0.05$ & & $p<0.05$ & & $\mathrm{p}<0.05$ \\
\hline
\end{tabular}

Note: For the analysis, a cut-off of less than 0.05 was used to determine the statistical difference.

$\mathrm{L} 1$ = level 1 group; L 2 = level 2 group; L $3=$ level 3 group

For further insight into identifying strategies that are less adopted by students we have analyzed three characteristics of level 1 group: the percentiles, their correlation with level 3 group and the value of mean score for each subscale. As it was already mentioned, the highest number of students (given in percentiles) is poorly practicing critical thinking, peer learning and help seeking. The comparison of number of students using low and those using high level (for each subscale) is presented as second column in Table 3. A huge difference between subscales was noticed and it was most expressed for critical thinking and help seeking. The number of students practicing low level of these subscales is few times higher than of students practicing at high level (2.69 times and 3.33 times, respectively). The value of mean scores is lowest for help seeking, critical thinking and peer learning, as well as for elaboration and organization strategies. When findings considering students in level 1 group were summarized, the subscales of critical thinking, peer learning and help seeking were found to be related with all of the three characteristics indicating those strategies as less adopted by the first-year students.

Table 3. Data of Level 1 group of first-year students

\begin{tabular}{|c|c|c|c|}
\hline Subscale & $\begin{array}{c}\% \text { of the } \\
\text { cohort }\end{array}$ & $\begin{array}{c}\text { Compared to } \\
\text { number of students } \\
\text { of L3 group }\end{array}$ & Mean score \\
\hline Rehearsal strategy & 15.59 & 0.44 & 3.39 \\
\hline Elaboration strategy & 8.25 & 0.18 & $2.94^{\mathrm{c}}$ \\
\hline Organization strategy & 10.09 & 0.21 & $2.90^{\mathrm{c}}$ \\
\hline Critical thinking & $39.45^{\mathrm{a}}$ & $2.69^{b}$ & $2.74^{\mathrm{c}}$ \\
\hline Self-regulating the learning & 12.84 & $1.40^{\mathrm{b}}$ & 3.34 \\
\hline Time and study environment & 11.92 & 0.55 & 3.30 \\
\hline Effort regulation & 12.84 & 0.34 & 3.26 \\
\hline Peer learning & $40.36^{\mathrm{a}}$ & $1.69^{\mathrm{b}}$ & $2.95^{\mathrm{c}}$ \\
\hline Help seeking & $36.69^{a}$ & $3.33^{\mathrm{b}}$ & $2.46^{\mathrm{c}}$ \\
\hline $\begin{array}{l}\text { Expected relation } \\
\text { L1 group : L3 group }\end{array}$ & & $\leq 1$ & \\
\hline Max score value of L1 group & & & 3.84 \\
\hline
\end{tabular}


Studying experience and adaptation may be expected to enhance adoption of higher level of learning strategies. To estimate whether the number of students practicing low level of learning strategies may be expected to decline over time, the percentage of level 1 group of the 1 st year were compared to the 2nd, 3rd and 4th year participants. Results are shown in Table 4. The percentiles are variable but progressive decline is not present. It was also of interest to check whether the least adopted strategies from the first-year students (critical thinking, peer learning and help seeking) become more used in later years of studying. Mean scores were used as indicators and data show that students of higher years of studying have also the lowest scores for the same strategies.

Table 4. Percentiles and mean scores of Levell group of students in $1^{\text {st }}, 2^{\text {nd }}, 3^{\text {rd }}$ and $4^{\text {th }}$ year

\begin{tabular}{|c|c|c|c|c|c|c|c|c|}
\hline \multirow{2}{*}{ Subscale } & \multicolumn{4}{|c|}{$\begin{array}{c}\text { Level } 1 \text { groups as } \\
\text { Percentile of the cohort }\end{array}$} & \multicolumn{4}{|c|}{$\begin{array}{l}\text { Level } 1 \text { groups } \\
\text { Mean scores }\end{array}$} \\
\hline & $1^{\text {st }}$ year & $\begin{array}{c}2^{\text {nd }} \\
\text { year }\end{array}$ & $\begin{array}{c}3^{\text {rd }} \\
\text { year }\end{array}$ & $\begin{array}{c}4^{\text {th }} \\
\text { year }\end{array}$ & $\begin{array}{c}1^{\text {st }} \\
\text { year }\end{array}$ & $\begin{array}{c}2^{\text {nd }} \\
\text { year }\end{array}$ & $\begin{array}{c}3^{\text {rd }} \\
\text { year }\end{array}$ & $\begin{array}{c}4^{\text {th }} \\
\text { year }\end{array}$ \\
\hline Rehearsal & $15.4 \%$ & $26.9 \%$ & $17.8 \%$ & $22.20 \%$ & 3.39 & 3.10 & 2.75 & 3.26 \\
\hline Elaboration & $8.1 \%$ & $6.7 \%$ & $5.5 \%$ & $4.40 \%$ & 2.94 & 3.25 & 2.62 & 3.12 \\
\hline Organization & $10.0 \%$ & $11.5 \%$ & $17.8 \%$ & $8.90 \%$ & 2.90 & 3.22 & 3.24 & 3.50 \\
\hline Critical thinking & $39.1 \%$ & $29.8 \%$ & $32.9 \%$ & $42.20 \%$ & 2.74 & 2.84 & 2.70 & 2.96 \\
\hline $\begin{array}{l}\text { Self-regulating the } \\
\text { process of learning }\end{array}$ & $12.7 \%$ & $16.3 \%$ & $23.3 \%$ & $22.2 \%$ & 3.34 & 3.35 & 3.29 & 3.36 \\
\hline $\begin{array}{l}\text { Time \& study } \\
\text { environment }\end{array}$ & $11.8 \%$ & $6.7 \%$ & $17.8 \%$ & $13.3 \%$ & 3.30 & 3.40 & 3.25 & 3.44 \\
\hline Effort regulation & $12.7 \%$ & $16.3 \%$ & $13.7 \%$ & $15.5 \%$ & 3.26 & 2.51 & 3.07 & 3.37 \\
\hline Peer learning & $40.0 \%$ & $37.5 \%$ & $41.1 \%$ & $57.8 \%$ & 2.95 & 2.51 & 2.46 & 2.71 \\
\hline Help seeking & $36.4 \%$ & $36.5 \%$ & $52.0 \%$ & $47.7 \%$ & 2.46 & 2.75 & 2.74 & 2.76 \\
\hline
\end{tabular}

\section{Discussion}

The objective of the study was to explore the level to which the first-year students of general medicine at the Ss. Cyril and Methodius University in Skopje are employing learning strategies, and to reveal the drawbacks of their learning methodology. These findings should help us reveal whether our students need assistance, and if so, to design and tailor where to best intervene to meet their needs. Learning strategies were investigated using MSLQ [12]. The reliability for the Learning Strategy Scales in this study is with excellent internal consistency (Cronbach's alpha 0.90). In their study Pintrich et al. [23] found the total reliability for these scales to be 0.89; Barker and Olsen [24] found it to be 0.88, while in a study of Vaculíková [25] the reliability coefficient ranged from 0.52 to 0.93 .

In our study the highest coefficient alphas $(0.84)$ is for critical thinking scale similar to the findings of Pintrich et al. [12], of Barker and Olsen [24] and Mc Sorley [26] - 0.80; 0.83 and 0.71, respectively. The lowest coefficient alphas is for Time and Study Environment Management, Help seeking and Elaboration strategy subscales $(0.44 ; 0.57$ and 0.58 , respectively). Pintrich et al. [12], Barker and Olsen [24] and McSorley [26] also found the lowest coefficient alphas for Help Seeking subscale (0.52 and 0.65, 0.37, respectively).

In general, the mean score value of the 109 first-year students is 4.94 showing that they use strategies for effective learning at the intermediate level (70.62\%). Similar are the results of Barker et al. [14] (4.98), Anais et al. [27] (4.53) and Hamid [28] (4.62). The comparison of the three scales of learning strategies shows that our students have higher scores on cognitive scale than on metacognitive and resource use scale. Same results are reported by Hamid and Singaram [28], but not by Barker et al. [14] whose respondents were the first-year engineering undergraduate students. 
Aiming to obtain more precise overview of the percentage of students who manage well versus those who struggle with learning strategies, we have defined three levels of learning strategy mastering. Three categories of score values have been also determined in Samarkoon et al. study [20], where low score was from 1.0 to 2.5 , medium from 2.5 to 5.0 and high scores from 5.0 to 7.0 [30]. Anais et al. [27] have qualified group average scores for subscales as low, medium or high. According to presented values, their low rank score averages were those $<3.8$ (representing $54.5 \%$ of the maximal value of the score and is similar to our low level); medium rank from $3.8<4.6$ (up to $75 \%$ of the maximal score) and high over 4.6 value of score.

As it was expected, our first-year students use different level of learning strategies. It is encouraging that the majority is in level 2 group and practice medium level of each subscale and even more, that $26 \%$ practice high level. Still, we cannot ignore the fact that a fifth of students $(20.89 \%)$ only use less than $55 \%$ of the instruments of each learning strategy. This is important because low level of learning strategies results in superficial learning, fragmented understanding of contents, poorer integration across topics, poorer academic achievements and further on, impaired ability to perceive and solve the problem given [6].

The distribution of our first-year cohort by level of usage of learning strategies enabled discovering which strategies are less adopted by a larger number of students. Also, the comparison of the number of students from level one and level three helps this study to depict less adopted subscales. They are: critical thinking, peer learning and help seeking strategy.

Critical thinking is an important tool of the cognitive processes, enabling active learning and understanding of the material through analysis of new ideas, linking of new ideas to already known concepts and using this knowledge for problem solving in unfamiliar contexts. For this reason, its adoption and high level implementation is favorable for effective learning. Wolters, Pintrich and Karabenick [31] are ranging the strategy of critical thinking as sophisticated strategies that individuals use for reasoning. We have found that our students poorly use this strategy. The findings of our project examining students' activities in small-group learning sessions [32] have shed more light to this problem. This same cohort of the first-year students took least participation in activities based on verbal communication: asking questions publicly; engaging in joint discussion and explanation and teaching to colleagues, which according to Gokhale [33] are essential instruments of critical thinking.

Peer learning and Help seeking are resource management strategies. Peer learning refers to a dialogue between and among peers and an intellectual exchange of ideas and information that can help students clarify course material and discover information they would not be able to on their own [34]. Observation of peers performing similar tasks also conveys to observers that they, too, are capable of accomplishing those particular tasks [12]. Anais et al. [27] reported that their students mostly practiced peer learning not as part of a learning routine but when experiencing difficulties with the learning process.

Help seeking is different from other learning strategies because it is also a social interaction. It refers to the process whereby students ask peers and instructors for proactive help in order to clarify confusing course material, thus expediting achievement. Avoiding seeking help when it is needed is associated with learning stagnation and poorer learning gains [35-37]. Intelligent tutoring systems should promote the development of skills for knowing when, why and where to seek help [38].

To what extent these findings for the first-year students should bother us, depends on whether in further years of studying the number of students practicing low level of learning strategies would significantly decline. The comparison with the number of students in level 1 groups from the 2nd, 3rd and 4th study years showed that their number does not progressively and significantly decrease. We believe that this is due to insufficient information given to 
students about learning strategies and their impact on learning outcomes, as well as to lecturedriven curriculum which have not influenced learning methodology [29].

Do our first-year students need assistance in adopting higher level of learning strategies? We are strongly convinced that short learning strategy training courses would awake students' awareness of the existence of cognitive, metacognitive and resource use strategies. Training should inspire them to apply the acquired strategy to learning activities and to later on evaluate its use and effectiveness. The final aim is to help students become able to transfer these strategies to new tasks and manage their studies. The research of Sobral [39] has shown that training could increase level of reflection as one of the basic instrument for deeper and effective learning. In the Renzulli [40] research, benefits from the initial study skills course are reported with evidence on how adopting strategies has improved students' performance.

Integration of MLSQ with the information system of the university may be a further useful step for students to gain clear insight into their strengths and weaknesses related to learning strategies. It should also be used for reviewing their progress in terms of learning. Cho et al. [30] suggest to evaluate students when enrolling at university, for better impression of the cohorts' needs. Based on the students' needs, teachers should adjust their teaching methods to demonstrate most of the learning strategies (group learning, critical thinking, communication competence training, peer teaching, think-aloud and help seeking).

Limitations: The current study was carried out on sample of students collected through voluntary survey. Consequently, the sample could not be regarded as fully representative. Secondly, as this was the first thorough examination of learning strategies of medical students in the Republic of North Macedonia, we were limited in terms of previous experiences in the field, for the discussion of results. Finally, some of the discussions and conclusions are based on conjectures that will require further research in order to be confirmed. In future, we need to consider the influence of the psychological, social and institutional context on students' learning strategies.

\section{Conclusion}

Macedonian students enrolled into the studies of general medicine represent a heterogeneous group regarding their level of learning strategy mastery. The majority of the students practice medium level of each subscale. Still, a significant portion of students utilize low level of learning strategies. A substantial difference in adoption of particular learning strategies has also been observed. Critical thinking, peer learning and help seeking are shown to be less frequently used by the first-year students. We cannot rely on expectation that learning experience by itself should increase the range of application of learning strategies, so a need for assistance in adopting and practicing more learning strategies is obvious. Based on the findings of this pilot study and other universities' experiences, an introductory course for learning strategies and their implementation in the content and methodology of teaching should be our task of priority.

\section{Acknowledgements}

The authors would like to acknowledge and express appreciation to the Dean of the Faculty of Medicine at Ss. Cyril and Methodius University in Skopje, Prof. Dr. Sonja Topuzovska and the Vice-Dean for Teaching, Prof. Dr. Beti Zafirova Ivanovska, for encouraging the initiation of this pioneering study and generously supporting its goals.

Conflict of interest statement. None declared. 


\section{References}

1. Subasinghe SD, Wanniachchi DN. Approaches to learning and the academic performance of a group of medical students-any correlation? Stud Med J 2009; 3: 5-10. Corpus ID: 53318482.

2. Weinstein C. Mayer R. The teaching of learning strategies. In: Wittrock M, editor. Handbook of Research on Teaching. 3rd ed. New York: MacMillan 1986; p: 315-327.

3. Weinstein C, Mayer R. The teaching of learning strategies. Innovation Abstracts 1983; 5(32). file:///C:/Users/User/AppData/Local/Temp/ED237180.pdf.

4. Zimmerman BJ, Schunk DH. Self-regulated learning and performance. In: BJ. Zimmerman, Schunk DH, editors. Handbook of self-regulation of learning and performance. New York: Routledge 2011; p: 1-12.

5. Zimmerman BJ. Becoming a self-regulated learner: An overview. Theory Pract 2002; 41(2): 64-70. doi: 10.1207/s15430421tip4102_2

6. Chonkar SP, Ha TC, Hang Chu SS, Xinhui NgA, Lim M, et al. The predominant learning approaches of medical students. BMC Med Educ 2018; 18:17-25. doi: 10.1186/s12909-018-1122-5.

7. Shaista H, Singaram VS. Motivated strategies for learning and their association with academic performance of a diverse group of 1st-year medical students. Afr J Health Prof Educ 2016; 8(1): 104-7. doi: 10.7196/AJHPE.2016.v8i1.757.

8. Kim KJ, Jang HW. Changes in medical students' motivation and self-regulated learning: a preliminary study. Int J Med Educ 2015; 6: 213-5. doi:10.5116/ijme.565e.of87.

9. Wickramasinghe DP, Samarasekera DN. Factors influencing the approaches to studding of preclinical and clinical students and postgraduate trainees. BMC Med Educ 2011; 11: 22-8. doi: 10.1186/1472-6920-11-22.

10. Bickerdike A, O’Deasmhunaigh C, O'Flynn S, O’Tuathaigh C. Learning strategies, study habits and social networking activity of undergraduate medical students. Int $J$ Med Educ 2016; 7: 230-6. doi:10.5116/ijme.576f.d074.

11. Stegers-Jager KM, Cohen-Schotanus J, Themmen A. Motivation, learning strategies, participation and medical school performance. Med Educ 2012; 46(7): 678-88. doi: 10.1111/J.1365-2923.2012.04284.x.

12. Pintrich PR, Smith DAF, García T, McKeachie WJ. A manual for the use of the motivated strategies questionnaire (MSLQ). Ann Arbor, MI: University of Michigan, National Center for Research to Improve Postsecondary Teaching and Learning, 1991.

13. Pintrich P, Roeser RW, De Groot EAM. Classroom and individual differences in early adolescents' motivation and self-regulated learning. J Early Adolesc 1994; 14(2): 139-61. doi: 10.1177/027243169401400204.

14. Barker JR, Olsen JP. Medical students learning strategies: Evaluation of first-year changes. University of Mississippi Medical Center, Department of Institutional Research, Jackson MS, 2002. https://www.msacad.org/journal/ejour2.html.

15. Cazan AM. Psychometric properties of cognitive self-regulation MSLQ scales. Rom J Exp Appl Psychol 2011; 2(1): 49-57. doi: 10.1016/j.sbspro.2014.03.227.

16. Cazan AM. Validity of the motivated strategies for learning questionnaire on a Romanian sample. Project: Self-regulated learning in academic context. Rev Psih 2017; 63(3): 151-62.

17. Rotgans J, Schmidts H. The Motivated Strategies for Learning Questionnaire: A Measure for Students' General Motivational Beliefs and Learning Strategies. AsiaPac Educ Res 2010; 19(2): 357-69. doi:10.3860/taper.v19i2.1603. 
18. McKeachie WJ, Pintrich PR, Lin YG, Smith DA. Teaching and Learning in the College Classroom. A Review of the Research Literature, National Center for Research to Improve Postsecondary Teaching and Learning, Michigan, 1987.

19. Frenkel S. Metacognitive Components in Learning to Learn Approaches, Int J Psychol: Biopsychosocial App 2014; 14: 95-112. doi:10.7220/2345-024X.14.5.

20. Roman JM, Gallego S. ACRA escalas de estrategias de aprendizaje. Madrid: TEA Ediciones 1994.

21. International Test Commission, International Guidelines on Test Adaptation, Available from: https://www.intestcom.org/files/guideline_test_adaptation.pdf.

22. Shurbanovska O, Blazhevska-Stoilkova B. Expectancy as a Mediator of the Relation between Learning Strategies and Academic Achievement among University Students, Psihološka istraživanja. 2013; XVI(1): 17-27.

23. Pintrich PR, Smith, DA, Garcia T, McKeachie WJ. Reliability and predictive validity of the Motivated for Learning Strategies Questionnaire (MSLQ). EPM 1993; 53(3): 801-14. https://doi.org/10.1177/0013164493053003024.

24. Barker JR, Olsen JP. Medical students' learning strategies: Evaluation of first-year changes. J Educ Psych 1995; 80: 321-31.

25. Vaculíková J. The Third Round of the Czech Validation of the Motivated Strategies for Learning Questionnaire (MSLQ). Int Educ Stud 2016; 9(7): 35-46. doi: 10.5539/ies.v9n7p35.

26. McSorley ME. The construct equivalence of the Motivated Strategies for Learning Questionnaire (MSLQ) for a South African context. Unpublished masters' treatise, University of Port Elizabeth, Port Elizabeth; 2004.

27. Anais MJ, Hojas AM, Bustos A, Letelier C, Zuzulich MS, Cabieses B, et al. Motivational and Cognitive Learning Strategies Used by First-Year Engineering Undergraduate Students at Universidad Catolica in Chile. Creat Educ 2012; 3 (Special issue): 811-17. doi:10.4236/ce.2012.326121.

28. Hamid S, Singaram VS. Motivated strategies for learning and their association with academic performance of a diverse group of 1st-year medical students. AJOL 2016; 8(1): 104-7. doi:10.7196/AJHPE.2016.V8I1.757.

29. Samarakoon L, Fernando Th, Rodrigo Ch, Rajapakse S. Learning styles and approaches among medical undergraduates and postgraduates. BMC Med Educ 2013; 13(1): 42-7. doi: 0.1186/1472-6920-13-42.

30. Cho KK, Marjadi B, Langendyk V, Hu W. Medical student changes in self-regulated learning during the transition to the clinical environment. BMC Med Educ 2017; 17: 59. doi: 10.1186/s12909-017-0902-7.

31. Wolters C, Pintrich P, Karabenick S. Assessing academic self-regulated learning. In: Moore K, Lippman L, eidtors. What do children need to flourish? Conceptualizing and measuring indicators of positive development. New York: Springer 2005; p: 251-70.

32. Milenkova L, Mitevska E, Kakasheva-Mazenkovska L, Petrova-Kostadinova I, Gerasimovska Z. Introduction of small-group active learning: how students' activities and the teacher's role in learning are being changed. Skopje: Ss. Cyril and Methodius University, Faculty of Medicine, Institute of Histology and Embryology; 2021. Project No. 1712/3.

33. Gokhale AA. Collaborative learning enhances critical thinking. J Tech Educ 1995; 7(1): 22-30. https://doi.org/10.21061/jte.v7i1.a.2.

34. Garcia T, Pintrich PR. Assessing students' motivation and learning strategies: The Motivated Strategies for Learning Questionnaire (MSLQ). Paper presented at the Annual Meeting of the American Educational Research Association, 1995; San Francisco, CA. ERIC Document Reproduction Service No: ED 383770. 
35. Aleven V, Mclaren B, Roll I, Koedinger K. Toward meta-cognitive tutoring: A model of help seeking with a Cognitive Tutor. IJAIED 2006; 16(2): 101-28.

36. Baker R, Gowda SM, Corbett AT. Automatically detecting a student's preparation for future learning: Help use is key. In: Proceedings of the 4th international conference on educational data mining; 2011; p: 179-88.

37. Bartholomé T, Stahl E, Pieschl S, Bromme R. What matters in help-seeking? A study of help effectiveness and learner-related factors. Comput Hum Behav 2006; 22(1): 113-29. https://doi.org/10.1016/j.chb.2005.01.007.

38. Roll I, Aleven V, McLaren BM, Koedinger KR. Improving students' help seeking skills using Metacognitive feedback in an intelligent tutoring system. Learning and Instruction 2011; 21(2): 267-80. https://doi.org/10.1016/j.learninstruc.2010.07.004.

39. Sobral DT. An appraisal of medical students' reflection-in-learning. Med Educ 2000; 34(3): 183-7. doi: 10.1046/j.1365-2923.2000.00473.x.

40. Renzulli SJ. Using Learning Strategies to Improve the Academic Performance of University Students on Academic Probation. NACADA J 2015; 35(1): 29-41. doi: 10.12930/NACADA-13-043. 